\title{
Avaliação das atividades antimicrobiana, citotóxica, moluscicida e antioxidante de Bromelia antiacantha Bertol. (Bromeliaceae)
}

\author{
MANETTI, L.M. ${ }^{1}$; TURRA, A.F. ${ }^{2}$; TAKEMURA, 0. S. $^{2}$; SVIDZINSKI, T.I.E. ${ }^{3}$; LAVERDE JUNIOR, A. ${ }^{1,2 *}$ \\ ${ }^{1}$ Instituto de Ciências Exatas, Agrárias, Tecnológicas e Geociências, Universidade Paranaense - UNIPAR, Praça \\ Mascarenhas de Moraes, s/n, Caixa Postal 224, CEP:87502-210, Umuarama-Brasil *laverde@unipar.br ${ }^{2}$ Instituto \\ de Ciências Biológicas, Médicas e da Saúde, UNIPAR, Praça Mascarenhas de Moraes, s/n, Caixa Postal 224. \\ CEP: 87502-210, Umuarama-Brasil ${ }^{3}$ LEPAC, Departamento de Análises Clínicas, Universidade Estadual de Maringá- \\ UEM, Avenida Colombo, 5790, CEP: 87020-900, Maringá-Brasil
}

\begin{abstract}
RESUMO: A Bromelia antiacantha Bertol. (Bromeliaceae), conhecida como gravatá ou caraguatá, apresenta características medicinais, alimentícias e ornamentais. Neste trabalho foram avaliadas as atividades antifúngica, antibacteriana, citotóxica, moluscicida e antioxidante de extratos alcoólicos das folhas e frutos desta espécie. $\mathrm{Na}$ avaliação da atividade antimicrobiana pelo método de microdiluição os extratos alcoólicos não foram eficientes frente à cepa referência do fungo Candida albicans (ATCC 90028), cepas clínicas de $C$. albicans e $C$. glabrata, e frente às bactérias S. aureus (ATCC 6538), P. aeruginosa (ATCC 9027) e E. coli (ATCC 8739). A atividade citotóxica, avaliada pelo bioensaio de toxicidade sobre náuplios de Artemia salina Leach (TAS), foi positiva para ambos extratos, com valores de $\mathrm{DL}_{50}$ variando em torno de $620 \mu \mathrm{g} \mathrm{mL}^{-1}$ e $360 \mu \mathrm{g} \mathrm{mL}^{-1}$, para os extratos alcoólicos dos frutos e das folhas, respectivamente. A atividade moluscicida, avaliada frente a caramujos da espécie Biomphalaria glabrata (Molusca, Gastropoda), não mostrou toxicidade aguda para soluções de $400 \mu \mathrm{g} \mathrm{mL}-1$. As propriedades antioxidantes dos extratos investigadas in vitro mediante o método de DPPH• foram consideradas modestas ( $35 \%$ de inibição na concentração de $\left.1000 \mu \mathrm{g} \mathrm{mL}^{-1}\right)$. Dentre as atividades biológicas que foram testadas a atividade citotóxica foi a mais pronunciada.
\end{abstract}

Palavras-chave: Bromeliaceae, Bromelia antiacantha, caraguatá, gravatá, atividade citotóxica

\begin{abstract}
Evaluation of antimicrobial, cytotoxic, molluscicidal and antioxidant activities of Bromelia antiacantha Bertol. (Bromeliaceae). Bromelia antiacantha Bertol. (Bromeliaceae), popularly known as "gravatá" or "caraguatá", shows medicinal, nutritional and ornamental properties. In the present study, the alcoholic extracts of leaves and fruits of this species were evaluated for antifungal, antibacterial, cytotoxic, molluscicidal and antioxidant activities. The alcoholic extracts evaluated by microdilution method were not efficient against the standard strain of Candida albicans (ATCC 90028), clinical strains of C. albicans and C. glabrata, and S. aureus (ATCC 6538), P. aeruginosa (ATCC 9027) and E. coli (ATCC 8739). The cytotoxic activity evaluated by toxicity bioassay on nauplii of Artemia salina Leach (TAS) was positive for both extracts, with $\mathrm{LD}_{50}$ values ranging around $620 \mu \mathrm{g} \mathrm{mL}^{-1}$ and $360 \mu \mathrm{g} \mathrm{mL}^{-1}$ for alcoholic extracts from leaves and fruits, respectively. The molluscicidal activity evaluated against Biomphalaria glabrata (Mollusca, Gastropoda) did not present acute toxicity for $400 \mu \mathrm{g} \mathrm{mL}^{-1}$ solutions. The antioxidant properties of the extracts investigated in vitro using the DPPH $\bullet$ method were considered modest $(\sim 35 \%$ of inhibition at $1000 \mu \mathrm{g} \mathrm{mL}^{-1}$ ). Among the evaluated biological activities, cytotoxic activity was the most marked.
\end{abstract}

Key words: Bromeliaceae, Bromelia antiacantha, "caraguatá", "gravatá”, cytotoxic activity

\section{INTRODUÇÃO}

A espécie Bromelia antiacantha Bertol., popularmente conhecida como caraguatá, gravatá, carauatá, croatá, é uma bromeliácea nativa da região sul e sudeste do Brasil (Lorenzi \& Matos, 2002; Vallés et al., 2007). Esta espécie apresenta hábito terrestre, chegando a alcançar 2 metros de altura. Normalmente

Recebido para publicação em 05/08/2008

Aceito para publicação em 06/08/2010

Rev. Bras. PI. Med., Botucatu, v.12, n.4, p.406-413, 2010. 
forma densos agrupamentos (reboleiras) e apresenta caules curtos, espessos e folhas longas, guarnecidas por espinhos (Reitz, 1983).

No sul do Brasil, os índios bororós ferviam os frutos para tratar a tosse e usavam como emolientes, uma tradição que foi continuada pelos colonizadores europeus (Reitz, 1983). A utilização na medicina popular é descrita como anti-helmíntica, antitussígena e no tratamento de cálculos renais. Os frutos são ácidos, purgativos, diuréticos, vermífugos e até abortivos (Reitz, 1983). Recomenda-se utilizálos na forma de xarope para os problemas respiratórios, enquanto que as folhas são usadas na forma de chá para bochechos e tratamento de afecções da mucosa bucal ou macerada como antitérmicas e anti-helmínticas (Correa, 1978; Reitz, 1983; Jorge \& Ferro, 1993; Lorenzi \& Matos, 2002; Santos et al., 2004). Em pequenas propriedades agrícolas, este vegetal também é usado como cerca viva, na extração de fibras e fabricação de sabão a partir dos frutos maduros. Os cachos são utilizados em arranjos decorativos em festas e celebrações (Reitz, 1983).

Outras espécies do gênero Bromelia também são usadas na medicina tradicional como vermífugas, anti-helmínticas, diuréticas, em casos de doenças respiratórias e problemas renais, desarranjos intestinais, diabetes, entre outras (Dorigoni et al., 2001; Garlet \& Irgang, 2001; Franco \& Barros, 2006; Agra et al., 2007). Porém poucas espécies deste gênero foram estudadas química e farmacologicamente (Manetti et al., 2009). Camacho-Hernández et al. (2002) observaram que os frutos da espécie $B$. pinguin, conhecida como fruto maia, apresentam atividade antifúngica contra Trichophyton spp. e Paecillomyces variotii. Segundo pesquisadores cubanos (Payrol et al., 2001), os extratos hidroalcoólicos dos frutos desta mesma espécie apresentaram atividade anti-helmíntica, porém, não demonstraram atividade antimicrobiana (Bacillus subtilis, B. turingiensis, Escherichia coli, Staphylococcus aureus e Candidaspp.).

Com relação à composição química, Raffauf et al. (1981) isolaram diterpenóides e flavonóides de $B$. pinguin. Da espécie $B$. plumieri, conhecida como piñuela, foram isolados dimetoxifenilato e antranilato, ambos glicosilados, sendo o segundo derivado do ácido antranílico, o qual é considerado um metabólito chave para a biossíntese de alcalóides e antibióticos (Parada et al., 1995; 1996).

Algumas espécies deste gênero também têm apresentado boas perspectivas como fonte de fibra natural, especialmente para a indústria automotiva, gerando opções de exploração sustentável em regiões amazônicas (Marques et al., 2007).

Considerando que o caraguatá apresenta características medicinais, alimentícias, ornamentais e industriais reunindo em única espécie um potencial múltiplo de aplicações (Correa, 1978; Reitz, 1983; Lorenzi \& Matos, 2002; Canela \& Sazima, 2005) e que se trata de espécie ainda muito pouco estudada, pretendeu-se com este trabalho avaliar potenciais atividades da mesma através de ensaios de atividade antimicrobiana, citotóxica, moluscicida e antioxidante (in vitro), visando levantar informações sobre as possíveis potencialidades biológicas.

\section{MATERIAL E MÉTODO}

\section{Material vegetal}

As folhas e frutos de Bromelia antiacantha Bertol. foram coletados (abril de 2007) no Horto de Plantas Medicinais da Universidade Paranaense (UNIPAR, Campus Sede, Umuarama - PR). A identificação da espécie foi feita pela Profa Dra Ezilda Jacomassi do Instituto de Ciências Biológicas, Médicas e da Saúde da UNIPAR - Campus Sede. A exsicata foi depositada no Herbário Educacional da Universidade Paranaense (HEUP), Paranavaí - PR, sob registro HEUP 2268.

\section{Preparação dos extratos}

Os frutos in natura foram triturados e submetidos à maceração por exaustão com etanol, resultando no extrato alcoólico dos frutos (EFR) após evaporação do solvente em rotaevaporador $\left(45^{\circ} \mathrm{C}\right)$. As folhas foram secas em estufa a $35^{\circ} \mathrm{C}$, com circulação de ar e depois trituradas. Uma parte desse material foi submetida à maceração com etanol, para a obtenção do extrato alcoólico bruto (EFO). Este foi concentrado em evaporador rotativo e disponibilizado para os testes de atividade. Outra parte do material seco e moído foi submetida à repetidas extrações com solventes de polaridades crescentes (hexano, acetato de etila e metanol) utilizando extrator Soxhlet, resultando nos extratos hexânico (EFOH), acetato de etila (EFOA) e metanólico (EFOM), após concentração em evaporador rotativo.

\section{Avaliação da atividade antimicrobiana}

A susceptibilidade antimicrobiana dos extratos foi avaliada através da técnica de concentrações inibitórias mínimas (CIMs), adaptada para produtos naturais, conforme descrito por Gazim (2005). As CIMs foram realizadas em quadruplicata pela técnica de microdiluição em caldo Müeller-Hinton (CMH) para bactérias. As cepas dos microorganismos utilizados foram Staphylococcus aureus (ATCC 6538), Escherichia coli (ATCC 8739) e Pseudomonas aeruginosa (ATCC 8027). Para a determinação da CIM, inicialmente foi preparada uma solução estoque de $100 \mathrm{mg} \mathrm{mL}^{-1}$ dos extratos EFR, EFO, EFOH, EFOA, EFOM, solubilizado em água

Rev. Bras. PI. Med., Botucatu, v.12, n.4, p.406-413, 2010. 
ou tween 80 à $2 \%$. Utilizando microplaca com 96 poços, foram adicionados $100 \mu \mathrm{L}$ da solução estoque (1:10) no primeiro poço, obtendo-se a concentração inicial de $100 \mathrm{mg} \mathrm{mL}^{-1}$. A partir desta concentração foi realizada diluição seriada, homogeneizando e transferindo $100 \mu \mathrm{L}$ do primeiro poço para o segundo e assim sucessivamente, até o décimo poço. Os dois últimos poços foram utilizados como controle positivo e negativo, contendo respectivamente $100 \mu \mathrm{L}$ do inóculo padronizado, conforme metodologia descrita por Bier (1985) (a partir da escala 0,5 Mac Farland, realizado diluição 1:50, e posteriormente, 1:20) e 100 $\mu \mathrm{L}$ de meio de cultura. As microplacas foram incubadas em estufa a $37^{\circ} \mathrm{C}$ por 48 horas. A CIM foi definida como a maior diluição em que houve inibição do crescimento, ou seja, ausência de turvação, quando comparada com o controle bacteriano ou de leveduras. Paralelo ao experimento foi realizado uma CIM para os antibióticos de referência (Penicilina e Tetraciclina).

Para a avaliação da atividade antifúngica, foram utilizadas leveduras, sendo a referência Candida albicans ATCC 90028 e dois isolados clínicos Candida albicans e Candida glabrata provenientes de pacientes que compareceram ao Laboratório de Ensino e Pesquisa em Análises Clínicas (LEPAC) da Universidade Estadual de Maringá para a realização de exames de secreção vaginal. As leveduras foram isoladas e identificadas seguindo os métodos clássicos usados em laboratórios clínicos (Rippon, 1974; Kurtzman \& Fell, 1998). A concentração inibitória mínima (CIM) foi avaliada pelo método de microdiluição em caldo, seguindo as normas de padronização preconizadas pelo National Committee for Clinical Laboratory Standards (NCCLS, 1997), publicadas no documento M27-A com as adaptações necessárias para produtos naturais.

$O$ teste foi realizado em microplacas plásticas esterilizadas contendo 96 poços organizados em oito séries identificadas de $A$ até $H$, cada qual com doze poços numerados de 1 a 12. Cada linha $(A-H)$ correspondeu a uma levedura (100 $\mu \mathrm{L}$ do inóculo aferido) e cada coluna recebeu 0 respectivo extrato em estudo (20 $\mathrm{mg} \mathrm{mL}^{-1}$; EFR, EFO, EFOH, EFOA, EFOM) diluído de forma seriada desde $1: 2$ até 1:1024. Em cada placa foram incluídos controles, negativo, positivo, do diluente e a levedura de referência Candida albicans (ATCC 90028). Após inoculação as placas permaneceram incubadas em estufa 35ㄷ por 48 horas com monitoramento diário. Após as 48 horas foi realizada a leitura do teste através de comparação visual, por reflexão em espelho. A CIM é considerada como a menor concentração do extrato capaz de inibir $100 \%$ do crescimento de cada levedura, tendo como referência o respectivo controle positivo.

\section{Avaliação da atividade citotóxica}

A atividade citotóxica preliminar dos extratos foi avaliada pelo bioensaio de toxicidade sobre náuplios de Artemia salina Leach (Meyer et al., 1982). Os ovos encistados de $A$. salina (Maramar) foram incubados em água do mar artificial à temperatura ambiente por 48 horas. Após a eclosão, dez náuplios de $A$. salina foram transferidos para tubos de ensaio contendo $5,0 \mathrm{~mL}$ água do mar artificial e os extratos (EFR, EFO, EFOH, EFOA, EFOM) a serem testados em diferentes concentrações $(1000,750,500,250$ e $100 \mu \mathrm{g} \mathrm{mL}^{-1}$ ). Os testes foram feitos em triplicata. Cada teste foi acompanhado de controle negativo (água salina e DMSO) e positivo com $\mathrm{K}_{2} \mathrm{Cr}_{2} \mathrm{O}_{7}\left(\mathrm{DL}_{50}=\right.$ 20 a $\left.40 \mu \mathrm{g} \mathrm{mL}^{-1}\right)$. A contagem dos animais vivos $\mathrm{e}$ mortos foi realizada após 24 horas. Os valores de $\mathrm{DL}_{50}$ dos extratos foram estabelecidos utilizando 0 método de Probitos, sendo considerados ativos quando $\mathrm{DL}_{50}<1000 \mu \mathrm{g} \mathrm{mL}^{-1}$ (Meyer et al., 1982).

\section{Avaliação da atividade moluscicida}

A verificação da atividade moluscicida em espécimes de Biomphalaria glabrata seguiu os procedimentos recomendados pela Organização Mundial de Saúde - OMS (WHO, 1965) e adaptações (Silva et al., 2008). Foram utilizados quatro caramujos adultos da espécie $B$. glabrata de tamanho uniforme (diâmetro da concha entre 10 e $12 \mathrm{~mm}$ ) criados em aquários a temperatura de $25^{\circ} \mathrm{C}$. Os testes preliminares (toxicidade aguda) foram realizados com os extratos brutos das folhas e frutos de $B$. antiacantha em duplicata. Os extratos EFR e EFO foram diluídos em água filtrada do aquário, sem cloro, com o auxílio de $100 \mu \mathrm{L}$ de DMSO na concentração inicial de $400 \mu \mathrm{g} \mathrm{mL}^{-1}$. Os moluscos ficaram em contato com a solução, por 24 e 48 horas, à temperatura ambiente. Foi realizada uma prova em branco apenas com o DMSO e como controle positivo a niclosamida $\left(1,0 \mu \mathrm{g} \mathrm{mL}^{-1}\right)$. A mortalidade foi avaliada a partir do acompanhamento dos batimentos cardíacos dos caramujos (24 e 48 horas) com auxílio de microscópio estereoscópico.

\section{Avaliação da atividade antioxidante}

A propriedade antioxidante dos extratos (EFR, EFO, EFOH, EFOA, EFOM) foi determinada por método espectrofotométrico avaliando a capacidade dos antioxidantes presentes nas amostras em seqüestrar o radical estável 2,2-difenil-1-picrilidrazil (DPPH•) (Molyneux, 2004). Foi preparada solução metanólica de DPPH • (marca Sigma) a $60 \mu \mathrm{M}$, de forma a apresentar absorbância em 515 nm entre 0,6 e 0,7. As determinações foram realizadas adicionando-se $2,90 \mathrm{~mL}$ da solução de DPPH・ e $0,10 \mathrm{~mL}$ dos extratos em estudo a tubos de ensaio. As frações foram testadas nas concentrações de 1000, 750, 500, 
250 e $100 \mu \mathrm{g} \mathrm{mL}^{-1}$. As leituras das absorbâncias foram realizadas em espectofotômetro (FEMTO, modelo 700 plus). Quercetina e Hidroxianisol de butila (BHA) foram utilizados como padrões positivos $\left(100 \mu \mathrm{g} \mathrm{mL}^{-1}\right)$. Todas as análises foram realizadas em triplicata com repetição $(n=6)$ e apresentadas em porcentagem de inibição (\%), calculados em relação à amostra controle (metanol+ DPPH $60 \mu \mathrm{M}$ ). Os desvios padrões foram dados em porcentagem de inibição. $A$ atividade antioxidante foi calculada através da equação

$\% \mathrm{DPPH}=\left[\left(\right.\right.$ Abs C “ Abs A) $\left.{ }^{*} 100\right] /($ Abs $\mathbf{C})$

onde Abs C e Abs A correspondem às absorbâncias do controle e da amostra, respectivamente (Molyneux, 2004).

\section{Caracterização fitoquímica dos extratos de B. antiacantha}

A fim de verificar a presença de alguns grupos de metabólitos secundários no material vegetal e no extrato vegetal, foi realizada a pesquisa dos metabólitos secundários através de testes de prospecção fitoquímica de acordo com metodologias adaptadas de Costa (1987), Matos (1988) e WHO (1998). Os constituintes pesquisados foram flavonoides heterosídeos, saponinas e taninos.

\section{RESULTADO E DISCUSSÃO}

Neste trabalho, foram apresentados os primeiros estudos de extratos das folhas e frutos de $B$. antiacantha quanto às atividades antifúngicas, antibacterianas, citotóxicas, moluscicidas e antioxidantes.

Considerando que os frutos e folhas do caraguatá são utilizados na medicina popular no tratamento de afecções da mucosa bucal e em casos de problemas respiratórios (Correa, 1978; Jorge \& Ferro, 1983; Reitz, 1983; Lorenzi \& Matos, 2002; Santos et al., 2004), no presente estudo foi avaliada a sensibilidade de alguns micro-organismos frente a extratos alcoólicos das folhas e frutos desta espécie.

Os extratos EFR, EFO, EFOH, EFOA, EFOM dos frutos e das folhas de $B$. antiacanthaforam avaliados frente às cepas de $C$. albicans, $C$. glabrata e da referência C. albicans (ATCC 90028). Todas as cepas testadas foram insensíveis aos extratos testados para a concentração inibitória mínima (CIM) superior à concentração de $10 \mathrm{mg} \mathrm{mL}^{-1}$, não apresentando atividade antifúngica (Tabela 1).

O teste de atividade antifúngica utilizou leveduras do gênero Candida, que vivem normalmente nos mais diversos nichos corporais, mas também podem ser agentes de infecções cutâneas ou sistêmicas de alta letalidade (Charles et al., 2005). Além de ser comum em infecções na mucosa bucal, a Candida albicans é o principal agente causal da candidíase vulvovaginal (Sheary \& Dayan, 2005), que segundo Sobel (1998) responde por 80 - 90\% dos casos. Dados mais recentes mostram o aumento de outras espécies chamadas de Candida não-albicans chegando a $40 \%$ dos casos (Consolaro et al., 2004). Essas espécies são consideradas de grande preocupação tendo em vista a tendência à resistência aos antifúngicos, dentre elas destaca-se a espécie C. glabrata. (Mohanty et al., 2007). Payrol et al. (2001) e Camacho-Hernández et al. (2002) avaliaram a susceptibilidade antifúngica de extratos metanólicos dos frutos de $B$. pinguin e também não observaram atividade antifúngica para Candida spp. Entretanto, os extratos desta espécie apresentaram atividade antifúngica contra várias cepas de Trichophytonspp. e também para Paecillomyces variotii (CamachoHernández et al., 2002).

Doenças respiratórias também podem ser

TABELA 1. Valores de concentração inibitória mínima (CIM) dos extratos de B. antiacantha Bertol. (Bromeliaceae) frente a fungos e bactérias Gram-positiva e Gram-negativas.

\begin{tabular}{lccccccc}
\hline \multicolumn{1}{c}{ Microrganismos } & \multicolumn{7}{c}{ CIM $\left(\mathrm{mg} \mathrm{mL}^{-1}\right)$} \\
\cline { 2 - 7 } & EFO & EFR & EFOM & EFOA & cont. 1 & cont. 2 & cont. 3 \\
\hline C. albicans (ATCC 90028) & $>10,0$ & $>10,0$ & $>10,0$ & $>10,0$ & 0,0005 & --- & --- \\
C. albicans (isol. clínico) & $>10,0$ & $>10,0$ & $>10,0$ & $>10,0$ & 0,0005 & --- & --- \\
C. glabrata (isol. clínico) & $>10,0$ & $>10,0$ & $>10,0$ & $>10,0$ & 0,001 & --- & --- \\
E. coli (ATCC 8739) & 10,0 & 10,0 & 10,0 & 10,0 & --- & $<0,0195$ & $<0,0195$ \\
P. aeruginosa (ATCC 9027) & $>10,0$ & 10,0 & 10,0 & 10,0 & --- & 0,039 & $<0,0195$ \\
\hline S. aureus (ATCC 6538) & $>10,0$ & 5,0 & 2,5 & 5,0 & --- & $<0,0195$ & $<0,0195$ \\
\hline
\end{tabular}

EFR: extrato alcoólico bruto dos frutos; EFO: extrato alcoólico bruto das folhas; EFOA: extrato acetoetilênico das folhas; EFOM: extrato metanólico das folhas; controle 1: nistatina; cont. 2: tetraciclina; cont. 3: penicilina.

Rev. Bras. PI. Med., Botucatu, v.12, n.4, p.406-413, 2010. 
causadas por várias bactérias, dentre as quais Staphylococcus aureus e Pseudomonas aeruginosa (Stefanello et. al., 2006). Como parte da avaliação antimicrobiana, os extratos dos frutos e folhas de caraguatá foram avaliados pelo método de microdiluição frente a cepas de bactérias Grampositiva e Gram-negativas bastante comuns como $S$. aureus (ATCC 6538), P. aeruginosa (ATCC 9027) e $E$. coli (ATCC 8739) (Tabela 1).

Verificou-se que apenas o EFOM de caraguatá apresentou leve atividade frente à bactéria Gram-positiva S. aureus. Apesar da baixa suceptibilidade observada, os resultados obtidos neste estudo sugerem que $B$. antiacantha não apresente metabólitos secundários com atividade antimicrobiana expressiva, não justificando, de certa forma, o uso popular das folhas e frutos desta espécie em casos de doenças respiratórias ou afecções bucais. Entretanto, as atividades atribuídas ao uso popular poderiam estar eventualmente relacionadas à composição proteolítica dos frutos, uma vez que várias bromeliáceas são reconhecidas como ricas em proteases (Vallés et al., 2007). Outra justificativa para dar suporte ao emprego do caraguatá como antitussígeno foi sugerida por Santos et al. (2009), na qual cristais de oxalato de cálcio seriam parcialmente responsáveis pelo mecanismo de ação expectorante dos frutos. Estes cristais, juntamente com açúcares ácidos, poderiam participar em parte no mecanismo de ação demulcente (suavizante), protegendo assim contra a inflamação (Ziment, 2002). Outra atividade biológica abordada neste estudo foi a citotoxicidade de extratos de $B$. antiacantha avaliada pela toxicidade sobre náuplios de Artemia salina. Este bioensaio tem mostrado boa correlação com a citotoxicidade sobre células $9 \mathrm{~Kb}$ e 9PS (leucemia), confirmando ser ferramenta útil para a determinação preliminar de atividade antitumoral (Meyer et al., 1982; McLaughlin, 1991). Os resultados do teste de citotoxicidade de todos os extratos de $B$. antiacantha mostraram que os extratos EFR (fruto), EFO e EFOM (folhas) apresentaram toxicidade frente a A. salina. Como os extratos EFOH e EFOA (folhas) apresentaram $\mathrm{DL}_{50}>1000 \mu \mathrm{g} \mathrm{mL}^{-1}$, os mesmos foram considerados inativos (Tabela 2). Para os extratos ativos (EFR, EFO e EFOM) foram calculados os valores de $\mathrm{DL}_{50}$, os quais corresponderam a 618,3, 362,1 e 275,9 $\mu \mathrm{g} \mathrm{mL}^{-1}$, respectivamente. De acordo com McLaughlin (1991), esses resultados sugerem que esta planta apresente atividade citotóxica moderada-fraca. A fraca atividade observada para EFR (frutos) corrobora com

TABELA 2. Resultados dos ensaios de letalidade frente a Artemia salina Leach (TAS).

\begin{tabular}{|c|c|c|c|c|c|}
\hline \multirow{2}{*}{ Extratos } & \multicolumn{5}{|c|}{ Náuplios so breviventes (\%) } \\
\hline & $1000 \mu \mathrm{g} \mathrm{mL}^{-1}$ & $750 \mu \mathrm{g} \mathrm{mL}^{-1}$ & $500 \mu \mathrm{g} \mathrm{mL}^{-1}$ & $250 \mu \mathrm{g} \mathrm{mL}^{-1}$ & $100 \mu \mathrm{g} \mathrm{mL}^{-1}$ \\
\hline $\begin{array}{l}\text { EFR } \\
\text { EFO }\end{array}$ & $\begin{array}{r}0,0 \\
30,0\end{array}$ & $\begin{array}{l}16,7 \\
30,0\end{array}$ & $\begin{array}{l}70,0 \\
50,0\end{array}$ & $\begin{array}{l}80,0 \\
96,7\end{array}$ & $\begin{array}{c}83,3 \\
100\end{array}$ \\
\hline $\mathrm{EFOH}$ & 83,0 & n.t. & n.t. & n.t. & n.t. \\
\hline EFOA & 80,0 & n.t. & n.t. & n.t. & n.t. \\
\hline EFOM & 0,0 & 0,0 & 0,0 & 70,0 & 100 \\
\hline $\mathrm{K}_{2} \mathrm{Cr}_{2} \mathrm{O}_{7}$ & n.t. & n.t. & n.t. & n.t. & 0,0 \\
\hline
\end{tabular}

EFR: extrato alcoólico bruto dos frutos; EFO: extrato alcoólico bruto das folhas; EFOH: extrato hexânico das folhas; EFOA: extrato acetoetilênico das folhas; EFOM: extrato metanólico das folhas; $\mathrm{K}_{2} \mathrm{Cr}_{2} \mathrm{O}_{7}$ : controle; n.t.: não testado.

resultados de Santos et al. (2009), que avaliaram a atividade citotóxica de extratos alcoólicos de frutos maduros de caraguatá sobre culturas de células de fibroblastos de ratos (L929) e não observaram citotoxicidade.

Brehmer (2005) realizou experimentos com extratos brutos de frutos de $B$. antiacantha entre outros, para avaliar o desenvolvimento de tumor ascítico de Ehrlich (TAE) em camundongos. $O$ tratamento indicou que os extratos de $B$. antiacantha apresentaram ação no desenvolvimento do TAE, diminuindo o crescimento e não alterando o número total de leucócitos da medula óssea.

Extratos aquosos e metanólicos das folhas e ramos da espécie $B$. pinguin também mostraram atividade citotóxica $\left(\mathrm{EC}_{50}\right.$ entre 2 e $\left.9 \mu \mathrm{g} \mathrm{mL}^{-1}\right)$ no ensaio com KB (kenacid blue), o qual avalia variações de proteínas totais em células (Raffauf et al., 1981). Assim como no ensaio com B. pinguin, também foi constatado que apenas os extratos mais polares de $B$. antiacantha apresentaram alguma atividade citotóxica.

Vários autores correlacionam a atividade citotóxica frente à $A$. salina como indicativo preliminar para a avaliação de outras atividades biológicas, além da antitumoral (Trotter et al., 1983; Fontenelle et al., 1988; Solis et al., 1993; Alves et al., 2000; Ruiz et al., 2005). Neste sentido, como forma de complementar o estudo de potenciais propriedades biológicas do caraguatá, a atividade moluscicida de extratos alcoólicos brutos das folhas (EFO) e frutos (EFR) foi avaliada devido à boa solubilidade em água e toxicidade moderada dos mesmos. Sabendo que

Rev. Bras. PI. Med., Botucatu, v.12, n.4, p.406-413, 2010. 
extratos brutos de plantas podem ser considerados ativos para valores de $\mathrm{DL}_{90}$ em concentrações abaixo de $100 \mu \mathrm{g} \mathrm{mL}^{-1}$ (Hostettman \& Marston, 1987), os extratos avaliados não poderiam constituir uma alternativa aos moluscicidas sintéticos, pois não foram ativos em concentração de $400 \mu \mathrm{g} \mathrm{mL}^{-1}$.

As propriedades antioxidantes dos extratos de caraguatá também foram investigadas neste trabalho. Acapacidade sequestradora de constituintes de plantas frente a radicais livres pode ser avaliada in vitro com êxito pelo teste do DPPH•, um radical livre estável a temperatura ambiente, com coloração violeta característica em solução metanólica. Este método se baseia na transferência de elétrons de um composto antioxidante para um radical livre, o DPPH•, que ao se reduzir perde a coloração púrpura (DuarteAlmeida et al., 2006). Os extratos brutos dos frutos e folhas de $B$. antiacantha foram avaliados por esta metodologia. Os resultados obtidos encontram-se na Figura 1. O percentual de inibição do radical livre de DPPH• observado para a concentração de $1000 \mu \mathrm{g}$ $\mathrm{mL}^{-1}$ foi bastante modesto. $\mathrm{O}$ extrato de polaridade média das folhas (EFOA) apresentou inibição da atividade antioxidante em torno de $35 \%$. Santos et

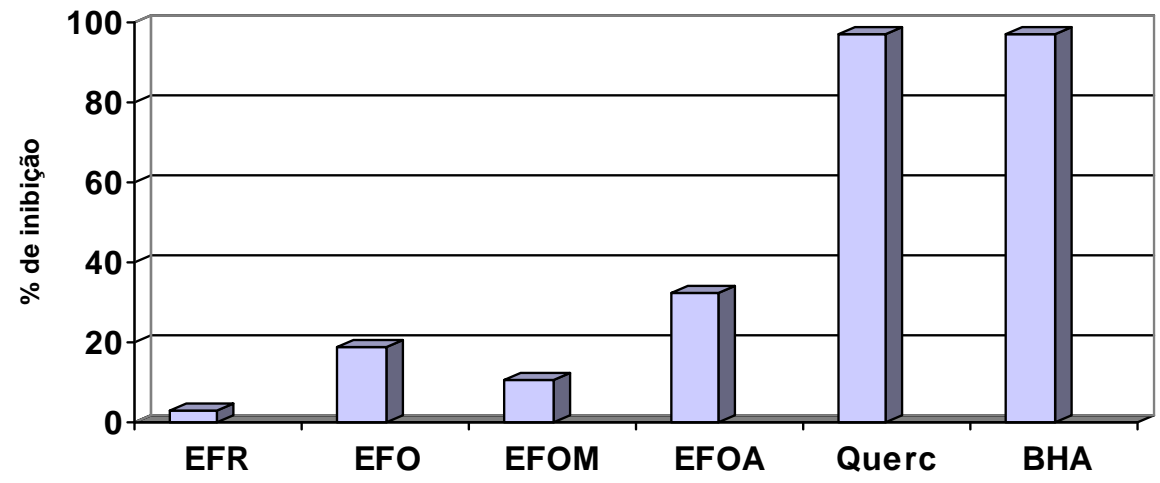

FIGURA 1. Percentual de inibição do radical de DPPH • dos extratos alcoólicos $\left(1000 \mu \mathrm{g} \mathrm{mL}^{-1}\right)$ das folhas e dos frutos de Bromelia antiacantha (Bromeliaceae) e dos padrões positivos quercetina $\left(100 \mu \mathrm{g} \mathrm{mL}^{-1}\right)$ e BHA $\left(100 \mu \mathrm{g} \mathrm{mL}^{-1}\right)$.

dos frutos empregando os métodos de $\mathrm{DPPH} \cdot$ e de complexo de fosfomolibidênio, a qual foi bastante baixa (5 mg mL-1), assim como os resultados observados no presente trabalho.

Ensaios fitoquímicos foram realizados com os extratos brutos no intuito de verificar a presença de flavonoides, taninos e saponinas, confirmando a presença de todos os grupos analisados. Santos et al. (2009) relataram a presença de derivados de flavonas e de ácidos hidroxicinâmicos nos frutos desta espécie. Desta forma, a atividade antioxidante observada para os extratos avaliados poderia ser atribuída à presença de compostos fenólicos, cuja ação antioxidante é conhecida na literatura (Heim et al., 2002; Arts \& Hollman, 2005). E a atividade citotóxica poderia estar eventualmente relacionada à presença de saponinas.

Enfim, dentre todas as atividades biológicas para as folhas e frutos da espécie $B$. antiacantha previamente avaliadas neste trabalho, concluiu-se que a atividade citotóxica frente à $A$. salina, embora considerada moderada, foi a que se mostrou mais pronunciada nos experimentos realizados.

\section{AGRADECIMENTO}

Nossos agradecimentos à Universidade Paranaense (UNIPAR) pelo apoio financeiro recebido e à Diretoria Executiva de Gestão da Pesquisa e da Pós-Graduação (DEGPP) pelo incentivo aos programas de iniciação científica (PIC e PIBIC) e de pesquisa docente (PIBIPP). À botânica Profa Dra Ezilda Jacomassi, pela identificação da planta.

\section{REFERÊNCIA}

AGRA, M.F.; FREITAS, P.F.; BARBOSA-FILHO, J.M. Synopsis of the plants known as medicinal and poisonous in Northeast of Brazil. Revista Brasileira de Farmacognosia, v.17, n.1, p.114-40, 2007.

ALVES, T.M.D. et al. Biological screening of Brazilian medicinal plants. Memórias do Instituto Oswaldo Cruz, v.95, n.3, p.367-73, 2000.

ARTS, I.C.W.; HOLLMAN, P.C.H. Polyphenols and disease risk in epidemiologic studies. American Journal of Clinical Nutrition, v.81, p.317S-25S, 2005.

BIER, O. Microbiologia e Imunologia. São Paulo: Melhoramentos, 1985. p.939-41.

BREHMER, J.S. Estudo de extratos de plantas medicinais no desenvolvimento do Tumor Ascítico de Ehrlich. 2005. 72p. Dissertação (Mestrado em Ciências da Saúde) - Centro de Ciências Farmacêuticas, Universidade do Vale do Itajaí, Itajaí.

CAMACHO-HERNÁNDEZ, I.L. et al. Antifungal activity of fruit pulp extract from Bromelia pinguin. Fitoterapia, v.73, p.411-3, 2002.

Rev. Bras. PI. Med., Botucatu, v.12, n.4, p.406-413, 2010. 
CANELA, M.B.F.; SAZIMA, M. The pollination of Bromelia antiacantha (Bromeliaceae) in Southeastern Brazil: Ornithophilous versus Melittophilous Features. Plant Boil, v.7, n.4, p.411-6, 2005.

CHARLES, P.E. et al. Candida spp. Colonization significance in critically ill medical patients: a prospective study. Journal of Intensive Care Medicine, v.31, n.3, p.393-400, 2005.

CONSOLARO, M.E.L. et al. Correlation of Candida species and symptoms among patients with vulvovaginal candidiasis in Maringá, Paraná, Brazil. Revista Iberoamericana de Micología, v.21, p.2002-5, 2004.

CORREA, M.P. Dicionário das plantas úteis do Brasil e das exóticas cultivadas. Rio de Janeiro: Ministério da Agricultura - IBDF, 1978. v.3,468p.

COSTA, A.F. Farmacognosia. Lisboa: Fundação Calouste Gulbenkian, 1987. v.2, 1107p.

DORIGONI, P.A. et al. Levantamento de dados sobre plantas medicinais de uso popular no município de São João do Polêsine, RS, Brasil. I - Relação entre enfermidades e espécies utilizadas. Revista Brasileira de Plantas Medicinais, v.4, n.1, p.69-79, 2001.

DUARTE-ALMEIDA, J.M. et al. Avaliação da atividade antioxidante utilizando sistema $\beta$-caroteno/ácido linoléico e método de sequestro de radicais $\mathrm{DPPH} \cdot$. Ciência e Tecnologia de Alimentos, v.26, n.2, p.446-52, 2006.

FONTENELLE, A.J. et al. A Avaliação da toxicidade de extratos de plantas medicinais através de bioensaio com Artemia salina Leach. Ciência e Cultura, v.40, n.11, p.1109-11, 1988.

FRANCO, E.A.P.; BARROS, R.F.M. Uso e diversidade de plantas medicinais no Quilombo Olho D’água dos Pires, Esperantina, Piauí. Revista Brasileira de Plantas Medicinais, v.8, n.3, p.78-88, 2006.

GARLET, T.M.B.; IRGANG, B.E. Plantas medicinais utilizadas na medicina popular por mulheres trabalhadoras rurais de Cruz Alta, Rio Grande do Sul, Brasil. Revista Brasileira de Plantas Medicinais, v.4, n.1, p.9-18, 2001.

GAZIM, Z. C. Determinação qualitativa e quantitativa dos constituintes químicos do óleo essencial de calêndula (Calendula officinalis L. Asteraceae) por cromatografia gasosa acoplada a espectrometria de massas (CG/EM) e a avaliação da atividade antimicrobiana e condições de plantio. 2005. 92p. Dissertação (Mestrado em Ciências Farmacêuticas) Departamento de Ciências Farmacêuticas, Universidade Estadual de Maringá, Maringá.

HEIM K.E.; TAGLIAFERRO A.R.; BOBILYAD.J. Flavonoid antioxidants: chemistry, metabolism and structure-activity relationships. Journal of Nutritional Biochemistry, v.13, n.10, p.572-84, 2002.

HOSTETTMANN, K.; MARSTON, A. Plant molluscicide research - an update. In: MORT, K.E. (Ed.). Plant molluscicides. Chichester: John Wiley, 1987. p.299-320. JORGE, L.I.; FERRO, V.O. Reconhecimento da espécie Bromelia antiacantha Bertol. Características botânicas e fitoquímicas. Revista de Farmácia Bioquímica USP, v.9, n.2, p.69-72, 1993.

KURTZMAN, C.P.; FELL, J.W. The yeast: a taxonomic study. 4.ed. New York: Elsevier, 1998. 1055p.

LORENZI, H.E.; MATOS F.J.A. Plantas medicinais no
Brasil - nativas e exóticas. Nova Odessa: Instituto Plantarum, 2002. 512p.

MANETTI, L.M.; DELAPORTE, R.H.; LAVERDE JÚNIOR, A. Metabólitos secundários da família Bromeliaceae. Quimica Nova, v.32, n.7, p.1885-97, 2009.

MARQUES, G.; GUTIÉRREZ, A.; DEL RIO, J.C. Chemical characterization of lignin and lipophilic fractions from leaf fibers of curaua. Journal of Agricultural and Food Chemistry, v.55, n.4, p.1327-36, 2007.

MATOS, F.J.A. Introdução a fitoquímica experimental. Fortaleza: Edições UFC, 1988. 124p.

McLAUGHLIN J.L. Crown gall tumors on potato discs and brine shrimp lethality: two simple bioassays for higher plant screening and fractions. In: DEY, P.M.; HARBONE, J.B. (Eds.). Methods in plant biochemistry. New York: Academic Press, 1991. p.1-32.

MEYER, B.N. et al. Brine shrimp: a convenient general bioassay for active plant constituents. Planta Medica, v.45, p.31-4, 1982.

MOHANTY, S. et al. Prevalence \& susceptibility to fluconazole of Candida species causing vulvovaginitis. Indian Journal of Medical Research, v.126, p.216-9, 2007. MOLYNEUX, P. The use of the stable free radical diphenylpicrylhydrazyl (DPPH) for estimating antioxidant activity. Songklanakarin Journal of Science and Technology, v.26, n.2, p.211-9, 2004.

NATIONAL COMMITTEE FOR CLINICAL LABORATORY STANDARDS (NCCLS). Method for Broth Dilution Antifungical Susceptibility Testing of Yeast; Approved Standard. Villanova, 1997. v.17, p.28. M27-A.

PARADA, F. et al. 3,4-dimethoxyphenyl- $\beta$-glucopiranoside from piñuela (Bromelia plumieri Kartens) fruit. Natural Product Letters, v.7, n.1, p.69-71, 1995.

PARADA, F. et al. 1-O- $\beta$-D-glucopiranosyl anthranilate from piñuela (Bromelia plumieri) fruit. Phytochemistry, v.42, n.3, p.871-3, 1996.

PAYROL, J.A. et al. Actividad farmacologica preliminar del fruto de Bromelia pinguin L. (piña de ratón). Revista Cubana de Farmácia, v.35, n.1, p.56-60, 2001.

RAFFAUF, R.F. et al. Diterpenoid and flavonoid constituents of Bromelia pinguin L. Journal of Organic Chemistry, v.46, n.6, p.1094-8, 1981.

REITZ, R. Bromeliáceas e a malária - bromélia endêmica. In: REITZ, R. (Ed.). Flora ilustrada catarinense. Itajaí: Herbário Barbosa Rodrigues, 1983. 856p.

RIPPON, J.W. Medical mycology: the pathogenic fungi and the pathogenic actinomycetes. Philadelphia: W.B. Saunders, 1974. 587p.

RUIZ, A.L.T.G. et al. Avaliação da atividade tóxica em Artemia salina e Biomphalaria glabrata de extratos de quatro espécies do gênero Eleocharis (Cyperaceae). Revista Brasileira de Farmacognosia, v.15, n.2, p.98102, 2005.

SANTOS, D.S. et al. Variação no período de germinação de sementes em uma população natural de Bromelia antiacantha Bertol. Revista Brasileira de Plantas Medicinais, v.6, n.3, p.35-41, 2004.

SANTOS, V.N.C. et al. Ripe fruits of Bromelia antiacantha: investigations on the chemical and bioactivity profile. Revista Brasileira de Farmacognosia, v.19, n.2A, p.35865, 2009.

SHEARY, B.; DAYAN, L. Recurrent vulvovaginal candidiasis. Australian Family Physician, v.34, n.3, p.147-50, 2005.

Rev. Bras. PI. Med., Botucatu, v.12, n.4, p.406-413, 2010. 
SILVA, N.F.S. et al. Bioensaio de atividade moluscicida adaptado para a avaliação de extratos de plantas medicinais. Arquivos de Ciências Veterinárias e Zoologia da UNIPAR, v.11, n.2, p.179-82, 2008.

SOBEL, J.D. Vulvovaginitis due to Candida glabrata. An emerging problem. Mycoses, v.12, S.2, p.18-22, 1998.

SOLIS, P. et al. A microwell cytotoxicity assay using Artemia salina. Planta Medica, v.59, n.3, p.250-2, 1993. STEFANELLO, M.E.A. et al. Avaliação da atividade antimicrobiana e citotóxica de extratos de Gochnatia polymorpha ssp floccosa. Revista Brasileira de Farmacognosia, v.16, n.4, p.525-30, 2006.

TROTTER, R.T. et al. Ethnography and bioassay: combined methods for a preliminary screen of home remedies for potential pharmacological activity. Journal of Ethnopharmacology, v.8, n.1, p.113-9, 1983.

VALLÉS, D.; FURTADO, S.; CANTERA, A.M.B. Characterization of news proteolytic enzymes from ripe fruits of Bromelia antiacantha Bertol. (Bromeliaceae). Enzyme and Microbial Technology, n.40, n.3, p.409-13, 2007.

WORLD HEALTH ORGANIZATION - WHO. Molluscicide screening and evaluation. Bulletin of the World Health Organization, v.33, p.567-76, 1965.

WORLD HEALTH ORGANIZATION - WHO. Quality Control Methods for Medicinal Plant Materials. Geneve: WHO, 1998. p.82-5.

ZIMENT, I. Herbal antitussives. Pulmonar Pharmacology Therapy, v.15, n.3, p.327-33, 2002. 